\title{
Cobertura vacinal do HPV Quadrivalente no estado do Piauí
}

\author{
Vacinal coverage of Quadrivalent HPV in the state of Piauí \\ Cobertura vacinal del VPH Cuadrivalente en el estado de Piauí
}

Lucília Graziele Rodrigues de Oliveira* ${ }^{1 *}$, Bruna Furtado Sena de Queiroz ${ }^{1}$, Ana Regina Machado Nunes $^{1}$, Deborah Bezerra Lopes da Silva ${ }^{1}$, Wemerson Gomes Silva ${ }^{1}$, Bianca de Oliveira Santos ${ }^{1}$, Alexandra Silva Pires ${ }^{1}$, Jallyne Viana Batista ${ }^{1}$, Jaiane Oliveira Costa $^{1}$, Maria Amélia de Oliveira Costa ${ }^{1}$.

\section{RESUMO}

Objetivo: Analisar a cobertura vacinal do HPV Quadrivalente em adolescentes no estado do Piauí. Métodos: Trata-se de uma pesquisa avaliativa, transversal descritiva, de abordagem quantitativa, através das informações colhidas do banco de dados do Programa Nacional de Imunização no período de 2017 a 2019. A análise dos dados foi realizada pelos softwares TabNet e Microsoft Excel. Resultados: A adesão a primeira dose da vacina, mesmo não atingindo a cobertura vacinal adequada (80\%), atingiu valores maiores do que a segunda dose, nenhuma das faixas etárias alcançou a meta vacinal. Conclusão: Os dados analisados mostram que a coberta vacinal está insuficiente, e existe uma adesão vacinal maior na primeira dose com relação à segunda dose, em ambos os sexos. Durante os anos em estudo percebe-se uma regressão na cobertura vacinal ao passar dos anos. É necessário que sejam intensificadas as ações de saúde e principalmente educação em saúde em todos os âmbitos possíveis de abrangência do público-alvo preconizado para vacinação, principalmente no que diz respeito ao retorno desses adolescentes a UBS.

Palavras-chave: Papilomavirus humano, Cobertura vacinal, Vacinação, Saúde pública.

\begin{abstract}
Objective: To analyze the vaccination coverage of Quadrivalent HPV in adolescents in the state of Piauí. Methods: This is an evaluative, cross-sectional, descriptive study, with a quantitative approach, using information collected from the database of the National Immunization Program in the period from 2017 to 2019. Data analysis was performed using the software TabNet and Microsoft Excel. Results: Adherence to the first dose of the vaccine, even if it did not reach the adequate vaccine coverage $(80 \%)$, reached higher values than the second dose, none of the age groups reached the vaccine target. Conclusion: The analyzed data show that the vaccination coverage is insufficient, and there is a greater vaccination compliance in the first dose in relation to the second dose, in both sexes. During the years under study, there is a regression in vaccination coverage over the years. It is necessary to intensify health actions and especially health education in all possible areas of coverage of the target public recommended for vaccination, especially with regard to the return of these adolescents to UBS.
\end{abstract}

Keywords: Human papillomavirus, Vaccination coverage, Vaccination, Public health.

\section{RESUMEN}

Objetivo: Analizar la cobertura de vacunación contra el VPH cuadrivalente en adolescentes del estado de Piauí. Métodos: Se trata de una investigación evaluativa, transversal, descriptiva, con enfoque cuantitativo, utilizando información recolectada de la base de datos del Programa Nacional de Inmunizaciones en el

${ }^{1}$ Centro Universitário UNIFACID/WYDEN, Teresina - PI. *E-mail: lucilia_oliveeira@hotmail.com 
período de 2017 a 2019. El análisis de los datos se realizó utilizando el software TabNet y Microsoft Excel. Resultados: La adherencia a la primera dosis de la vacuna, aunque no alcanzó la cobertura adecuada de la vacuna $(80 \%)$, alcanzó valores superiores a la segunda dosis, ninguno de los grupos de edad alcanzó la meta de la vacuna. Conclusión: Los datos analizados muestran que la cobertura de vacunación es insuficiente y existe un mayor cumplimiento de vacunación en la primera dosis en relación a la segunda dosis, en ambos sexos. Durante los años en estudio, hay una regresión en la cobertura de vacunación a lo largo de los años. Es necesario intensificar las acciones de salud y especialmente la educación en salud en todas las áreas posibles de cobertura del público objetivo recomendado para la vacunación, especialmente en lo que respecta al retorno de estos adolescentes a la UBS.

Palabras clave: Virus del papiloma humano, Cobertura de vacunación, Vacunación, Salud pública.

\section{INTRODUÇÃO}

O papilomavírus humano (HPV) é um vírus de extrema relevância entre as infecções sexualmente transmissíveis (IST), sendo um grande problema para a saúde mundial, devido a sua alta potência de causar doença oncogênica. As estimativas de mulheres infectadas pelo HPV no mundo são de aproximadamente 291 milhões de mulheres portadoras do HPV, sendo os tipos 16 e 18 responsáveis por $32 \%$ dessas infecções. Calcula-se também que $25 \%$ a $50 \%$ da população feminina no mundo já esteja infectada pelo HPV, assim como 50\% da população masculina mundial também faz parte desses índices (INCA, 2017; BRASIL, 2013).

A infecção pelo HPV está relacionada a diversos fatores, como a carga viral e aspectos intrínsecos ao hospedeiro, como multiparidade, higiene precária, início de vida sexual precoce, alimentação inadequada, tabagismo, uso de contraceptivos orais, infecção por outros patógenos de transmissão sexual como o Herpes vírus do tipo 2, Clamydia Trachomatis e o Vírus da Imunodeficiência Humana (HIV). Além disso, o grande número de parceiros sexuais que o indivíduo se relacionou durante a vida sexual é um fator primordial para a contaminação pelo vírus (WRIGHT TC, et al., 2015; SUN LL, et al., 2015).

O vírus pode ser transmitido de várias formas, como o contato com órgãos genitais por meio da prática sexual, por relações anais e sexo oral, contaminação materno-fetal, intra ou periparto, por meio do líquido amniótico ou no trabalho de parto. Outra forma de contaminação se dá por materiais contaminados ou esterilizados inadequadamente em procedimentos ginecológicos, e ainda através de objetos pessoais como toalhas e roupas íntimas. O mesmo apresenta um período de incubação que varia de três semanas a oito meses, podendo as lesões permanecerem por anos na forma subclínica, tendo em sua maioria a regressão espontânea, sendo a presença do vírus insuficiente para o desencadeamento de alterações malignas (BRASIL, 2018; ROSA ML, et al., 2009; CONTI FS, et al., 2006; DIÓGENES MAR, et al., 2006).

Dentre as diversas formas de prevenção dessa infecção, a mais eficaz é a vacinação. No Brasil é disponibilizada a vacina quadrivalente que contempla os vírus tipo $6,11,16$ e 18, tanto para as meninas quanto para os meninos, sendo as meninas na faixa etária de 09 a 14 anos de idade e os meninos de 11 a 14 anos de idade, sendo oferecida pelo Programa Nacional de Imunização (PNI) nas unidades básicas de saúde e também nas escolas, tendo em vista que essa faixa etária passa boa parte do tempo em ambiente escolar, sendo dessa forma um ambiente ideal para realização de campanhas de vacinação (CARNEIRO RF, 2014).

O PNI é referência a nível global por sua diversidade de imunobiológicos e, em 2014 implantou a vacina do HPV (Papiloma Vírus) no calendário Nacional de vacinação. A introdução da vacina se justifica pelas estimativas mundiais que indicam cerca de 530 mil casos novos e 275 mil mortes decorrentes de câncer do colo do útero ao ano, onde este vírus muito contribui nessas estimativas, com $88 \%$ em países que estão em desenvolvimento, se constituindo a segunda causa de morte por câncer no Brasil (BRASIL, 2014).

No Brasil, a cobertura vacinal no período de 2013 a maio de 2017 com a segunda dose da vacina quadrivalente contra o HPV em meninas de 9 a 15 anos foi $45,1 \%$, sofrendo uma queda significativa em detrimento à cobertura com a primeira dose $(72,4 \%)$. Na população masculina, a cobertura vacinal de uma 
dose no ano de 2017 foi ainda menor (16,5\%). Possíveis fatores que podem ter contribuído para a baixa cobertura incluem o receio de reações adversas, o crescimento acentuado do movimento antivacina e os desafios logísticos da volta da administração da vacina para o ambiente das unidades básicas de saúde (BRASIL, 2017).

Considerado uma importante ferramenta para a tomada de decisão nas diversas esferas de gestão, o indicador de cobertura vacinal, consegue fornecer informações acerca dos níveis de cobertura, visto que, somente com coberturas suficientes é possível alcançar o controle ou, manter doenças evitáveis em condições de prevenção ou erradicação (BRASIL, 2015). No Brasil a meta vacinal de toda a população é de $80 \%$, sendo constituída por 4,16 milhões de adolescentes, tendo os Estados e Municípios que estabelecerem mecanismos para obter sucesso na vacinação e assim atingir a cobertura vacinal. Um recurso adicional sugerido é a vacinação escolar, tendo em vista que em outros países que adotaram esse método, foi evidenciado contribuições para alcançar e manter o foco da vacinação (BRASIL, 2015).

Diante disso, o presente estudo justifica sua relevância, pois calcular a cobertura vacinal do HPV é crucial para identificar o progresso ou o retrocesso da vacinação no Brasil, sendo evidente que essa vacina foi marcada por adversidades envolvendo a inclusão gradual das faixas etárias, divulgação de informações contrárias à vacinação e ocorrência de eventos adversos (MOURA LL, 2019). Desse modo, se dá a importância da cobertura vacinal, pois somente com coberturas adequadas é possível prevenir e manter sob controle as doenças passíveis de imunização.

Com base neste contexto, este estudo tem como objetivo analisar a cobertura vacinal do HPV Quadrivalente em adolescentes no estado Piauí no período de 2017 a 2019, bem como identificar as faixas etárias e os sexos que alcançaram a meta da cobertura vacinal, relacionando os fatores que interferem na adesão à vacinação, contextualizando os achados com a cobertura vacinal na literatura.

\section{MÉTODOS}

O presente estudo trata-se de uma pesquisa avaliativa, que se caracteriza como transversal descritiva, de abordagem quantitativa sendo sua natureza descritiva. Por se tratar de um banco de dados de domínio público, não houve necessidade de submissão do estudo ao Comitê de Ética e Pesquisa (CEP). Os dados da pesquisa foram coletados a partir do banco de dados do Sistema de Informações do Programa Nacional de Imunizações (SI-PNI), o qual alimenta o Departamento de Informática do Sistema Único de Saúde (DATASUS).

A pesquisa teve como cenário de estudo o Sistema de Informações do Programa Nacional de Imunizações (SI-PNI). A população do estudo foi relacionada com base nos dados relativos a cobertura vacinal no estado do Piauí entre os anos de 2017 a 2019. Após análise da população, foram adotados os seguintes critérios de inclusão: meninas de 09 a 14 anos e meninos de 09 a 14 anos que receberam as doses da vacina HPV Quadrivalente.

Os dados para a construção da cobertura vacinal do HPV Quadrivalente foram coletados no mês de junho de 2020, obtidos através do banco de dados do Programa Nacional de Imunização correspondente ao ano de 2017 a 2019. Esses dados foram organizados em gráficos, acompanhados do componente descritivo do estudo. Para o processamento de dados, foram utilizados recursos da informática, a exemplo do Microsoft Office Excel e TABNET.

\section{RESULTADOS E DISCUSSÃO}

A análise da cobertura vacinal do HPV Quadrivalente referente a primeira e a segunda dose, tanto no sexo feminino quanto no sexo masculino, correspondente ao período de 2017 a 2019 no Estado do Piauí, mostrou que a adesão a primeira dose da vacina, mesmo não atingindo a cobertura vacinal adequada (80\%), atingiu valores maiores do que a segunda dose (Gráfico 1). 
Gráfico 1- Cobertura vacinal HPV Quadrivalente $1^{\underline{a}}$ e $2^{\underline{a}}$ dose no sexo masculino, na faixa etária de 11 a 14 anos.

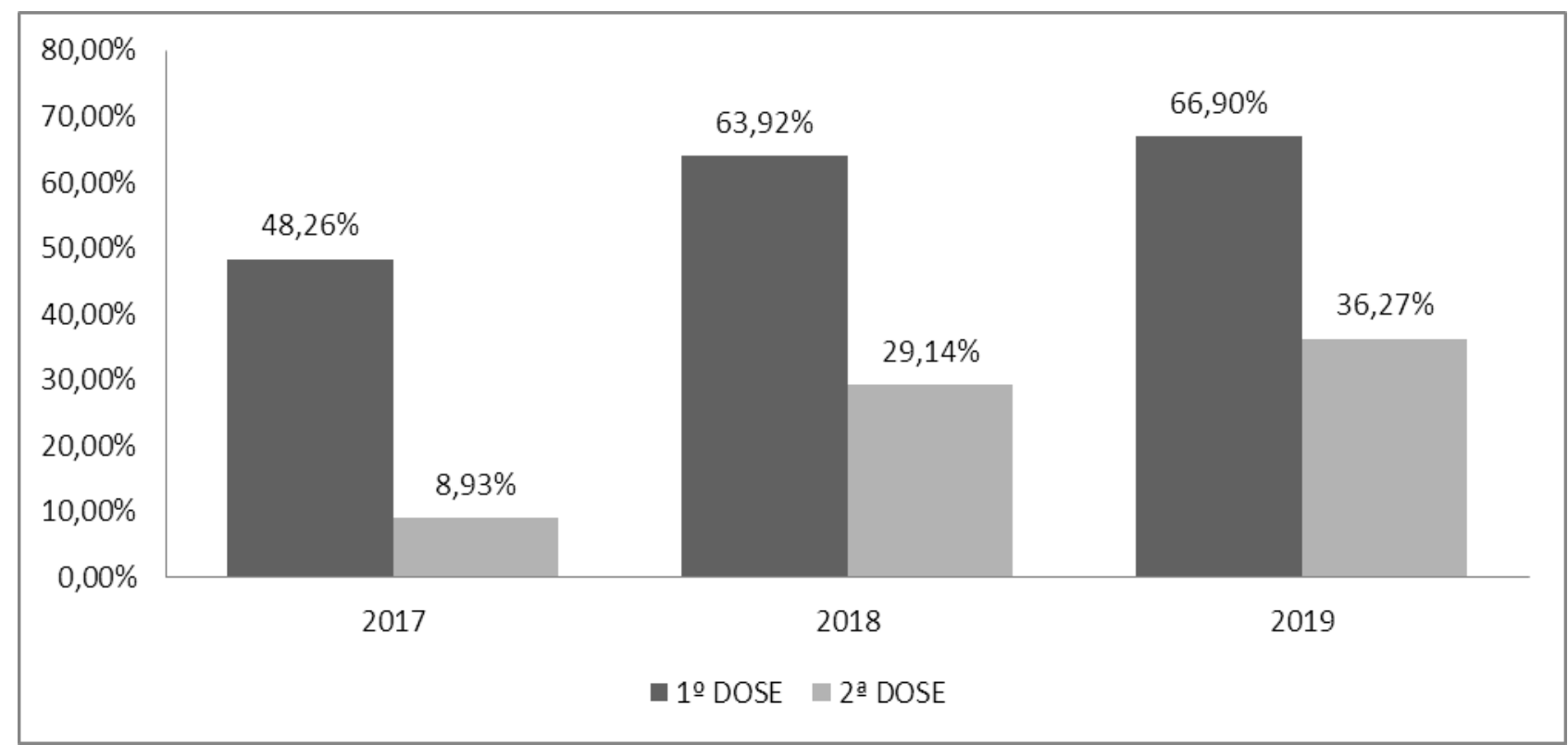

Fonte: Oliveira LGR, et al., 2020. Dados extraídos do SIPNI/DATASUS, 2020.

Observa-se que o sexo masculino no ano de 2019 atingiu a maior cobertura vacinal com a primeira dose $(66,90 \%)$, e apresentou uma evolução significativa na adesão à segunda dose da vacina ao passar dos anos, atingindo sua maior cobertura vacinal com a segunda dose. Nota-se que no ano de 2017, período em que a vacina foi implementada no calendário vacinal para o sexo masculino, houve uma baixa adesão vacinal, atingindo valores menores que $50 \%$ em ambas as doses.

Com referência ao sexo feminino, percebe-se que atingiu sua maior cobertura vacinal com a primeira dose $(69,14 \%)$ no ano de 2017 e manteve padrões percentuais abaixo de $50 \%$ na segunda dose durante os anos presentes no estudo (Gráfico 2).

Gráfico 2 - Cobertura vacinal HPV Quadrivalente $1^{\underline{a}}$ e $2^{\underline{a}}$ dose no sexo feminino, na faixa etária de 9 a 14 anos.

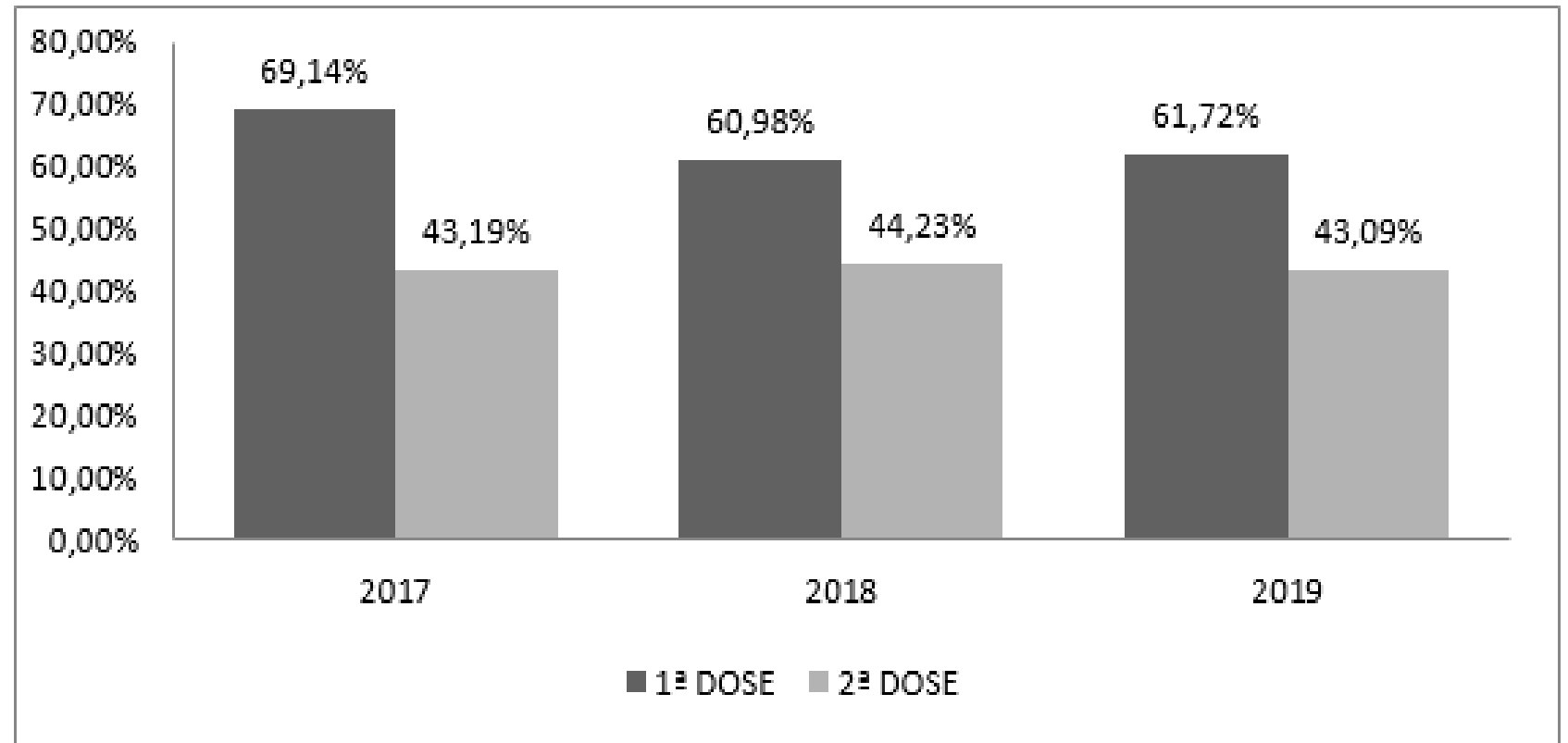

Fonte: Oliveira LGR, et al., 2020. Dados extraídos do SIPNI/DATASUS, 2020. 
Nos registros do Ministério da Saúde do Brasil foi verificado que em 2017 houve adesão de grande parte das meninas de 9 a 14 anos na primeira dose, porém menos da metade retornou para receber a segunda dose (BRASIL, 2018).

A baixa cobertura vacinal observada nos gráficos, principalmente na segunda dose, em ambos os sexos, tem como um dos principais fatores a mudança do local para realização da vacina, que saiu das escolas para a UBS, tendo em vista que nas escolas se concentrava uma grande quantidade do público-alvo. Bem como a falta de conhecimento sobre a importância do cumprimento do esquema vacinal recomendado, uma vez que a aplicação de somente uma dose da vacina não confere imunização satisfatória.

É de extrema importância que os adolescentes recebam o esquema completo da vacina contra o HPV o mais precocemente possível, preferivelmente antes de se tornarem sexualmente ativos. Recebendo corretamente o esquema vacinal o adolescente que recebe corretamente o esquema vacinal apresenta uma eficácia de 98\% (ALMEIDA GCP, 2014; BRASIL, 2015).

Relacionando a cobertura vacinal do HPV Quadrivalente por faixa etária, observa-se que no sexo masculino, o grupo etário que teve maior adesão à vacinação foi representado pelas idades de 13 e 14 anos, obtendo coberturas acima da meta estabelecida, respectivamente nos anos de $2018(81,25 \%)$ e 2019 (87,28\%). Apresentando grande importância no que diz respeito à prevenção do HPV por esse público, uma vez que os homens são os principais transmissores da doença (Gráfico 3).

Gráfico 3 - Cobertura vacinal do HPV Quadrivalente $1^{\text {a }}$ dose na população masculina, na faixa etária de 11 a 14 anos.

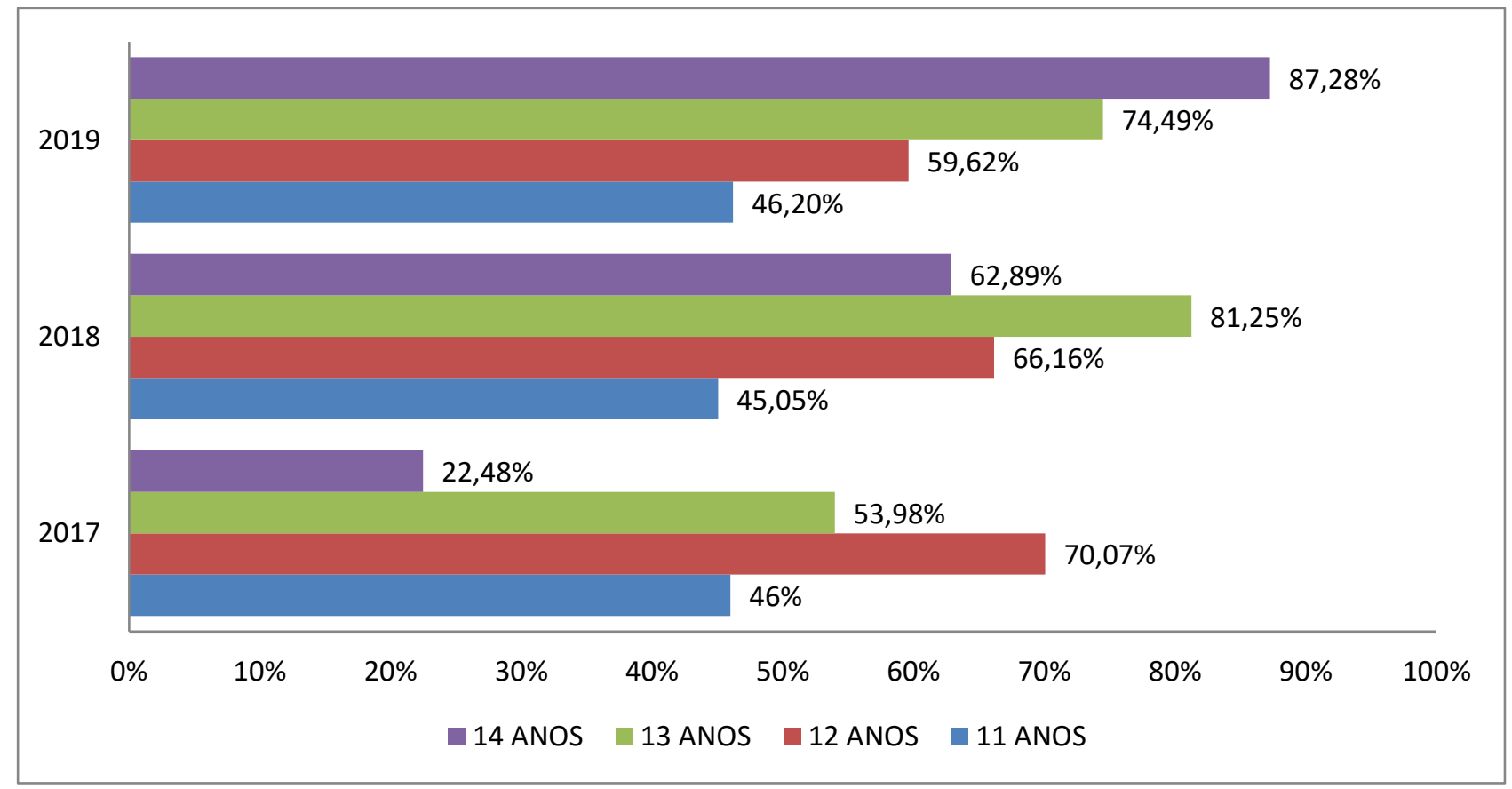

Fonte: Oliveira LGR, et al., 2020. Dados extraídos do SIPNI/DATASUS, 2020.

Para a faixa etária de 12 anos foi observado que mesmo não sendo atingida a meta vacinal, manteve uma cobertura vacinal acima de 50\%, com um percentual de $70,07 \%$ no ano de 2017 . Já os meninos de 11 anos mantiveram percentuais abaixo de $50 \%$ em todos os anos. No que se refere à cobertura vacinal com a segunda dose, podemos observar no gráfico abaixo, que em todos os anos a meta vacinal não conseguiu ser atingida, chegando a apresentar o percentual de cobertura vacinal de $(1,77 \%)$, no ano de 2017 , para a faixa etária de 09 anos, no ano de implementação da vacina. Fator este que pode estar associado ao fato da disponibilidade dos pais em levarem seus filhos para a UBS, tendo em vista que são faixas etárias que necessitam de supervisão, bem como o desconhecimento sobre a vacina e a preocupação com eventos adversos (Gráfico 4). 
Gráfico 4 - Cobertura vacinal do HPV Quadrivalente $2^{\text {a }}$ dose na população masculina, na faixa etária de 11 a 14 anos.

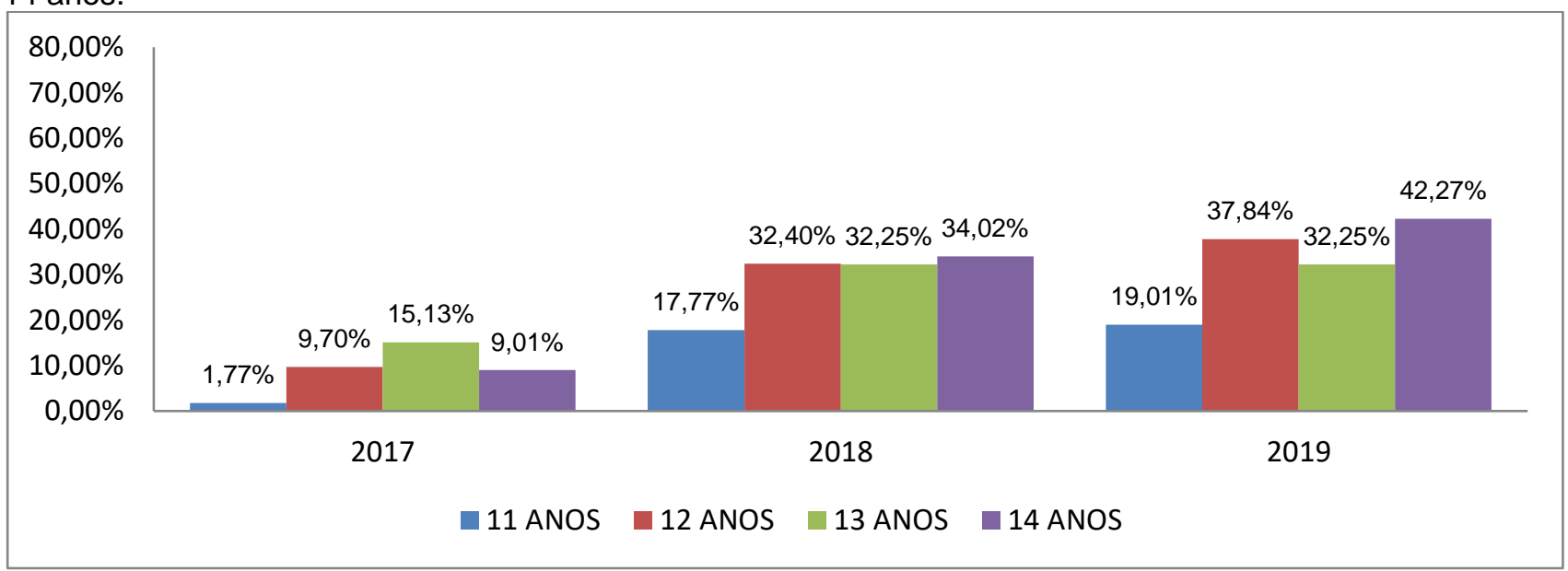

Fonte: Oliveira LGR, et al., 2020. Dados extraídos do SIPNI/DATASUS, 2020.

Diante disso, Zanini NV, et al. (2017); relata que diversos fatores são apontados na literatura sobre a recusa da vacina do HPV, dentre eles destacam-se o medo dos efeitos adversos e a impossibilidade de ir até a unidade de saúde para vacinar-se. Bem como também o desconhecimento sobre o vírus, formas de transmissão e possíveis complicações, desconhecimento sobre o benefício da vacina e preocupação dos responsáveis com os efeitos adversos.

Com referência a análise, por faixa etária na população feminino, observa-se que na primeira dose em todos os anos pelo menos uma das faixas etárias conseguiu atingir a cobertura vacinal, tendo no ano de 2017 na faixa etária de 11 anos a cobertura de $83,72 \%$ e na faixa etária de 14 anos uma cobertura vacinal de 104,83\%, seguido do ano de 2018 na faixa etária de 12 anos com uma cobertura de 84,14\% e no ano de 2019 uma cobertura de $85,18 \%$ na faixa etária de 13 anos. E as faixas etárias iniciais de 09 e 10 anos mantendo sempre percentuais abaixo da meta vacinal estabelecida (Gráfico 5).

Gráfico 5 - Cobertura vacinal do HPV Quadrivalente $1^{1 \underline{a}}$ dose na população feminina, na faixa etária de 9 a 14 anos.

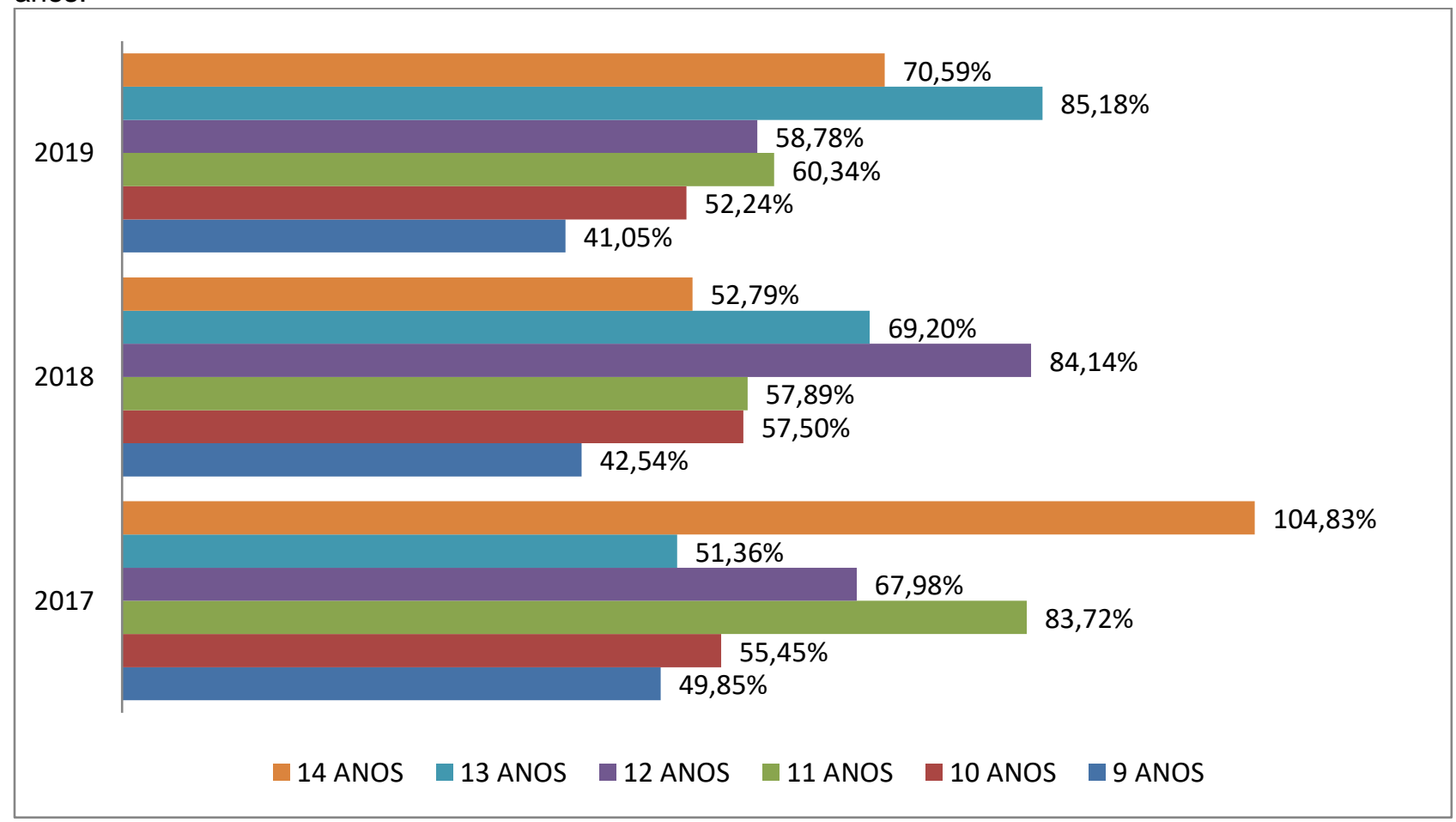

Fonte: Oliveira LGR, et al., 2020. Dados extraídos do SIPNI/DATASUS, 2020. 
A baixa adesão vacinal nas faixas etárias iniciais, pode ser justificada pelo desconhecimento dos pais acerca da vacina e seus benefícios, levando-os a atribuição da vacinação do HPV como fator que influencia na iniciação da vida sexual desses adolescentes.

A recomendação da imunização de meninas desde muito novas, antes do seu início a vida sexual, gera uma discussão acerca da aceitação da vacina e tem efeito na adesão do público-alvo, tornando essa indicação muitas vezes não bem recebida e compreendida pela família (DA FONSÊCA AC, et al., 2017; CAMPOS ERT, et al., 2017).

No que se refere à cobertura vacinal na população feminina com a segunda dose, observa-se no gráfico abaixo, que as faixas etárias de 13 e 14 anos foram as que conseguiram atingir uma melhor cobertura vacinal, embora nenhuma das faixas etárias tenha alcançado a meta vacinal. A idéia de que a vacina irá estimular a sexualidade desses adolescentes e uma possível introdução das mesmas na vida sexual, é um tabu existente entre os pais e na população, dificultando à adesão a vacina e evitando a proteção pelo método mais eficaz que é a vacinação (Gráfico 6).

Gráfico 6 - Cobertura vacinal do HPV Quadrivalente $2^{2}$ dose na população feminina, na faixa etária de 9 a 14 anos.

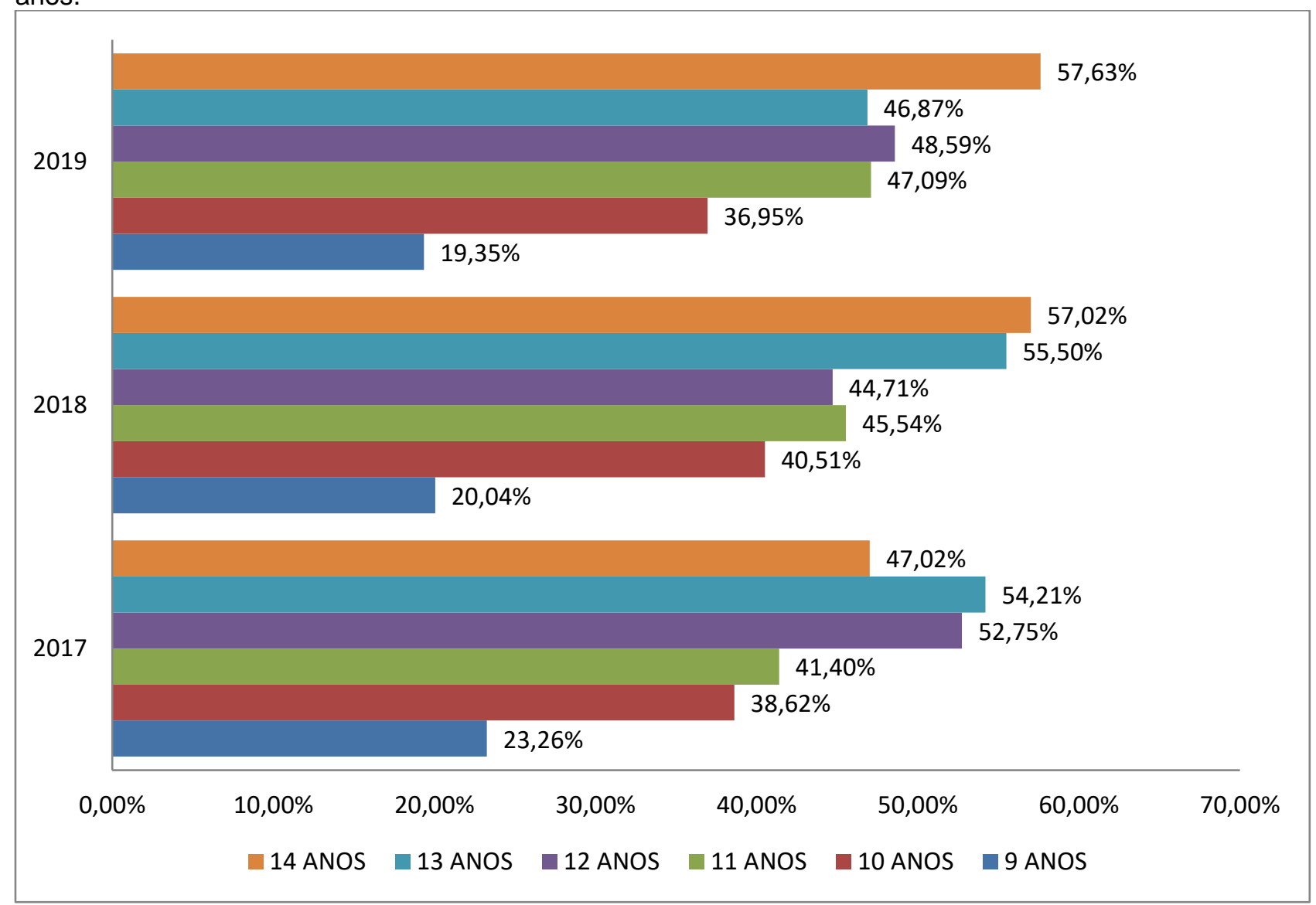

Fonte: Oliveira LGR, et al., 2020. Dados extraídos do SIPNI/DATASUS, 2020.

Essa dificuldade de aceitação e compreensão dos pais no que se refere ao entendimento de que a vacina previne o contágio por uma IST acaba gerando discussões sobre a sexualidade dos adolescentes e 0 alerta de que a vacinação é vista somente como obrigação para prevenção de uma IST e não como um problema de saúde pública (POMFRET TC, et al., 2011).

Tal discussão acaba representando a falta de conhecimento dos pais sobre o assunto e expondo a necessidade de uma orientação correta por parte dos governos, escolas, profissionais e instituições de saúde sobre o tema para a população (SANTOS ACD, et al., 2019; RODEN R, et al., 2006; ROSA MI, et al., 2009). 
Desde sua implementação, a vacina é vista prioritariamente como esse fator de interferência sexual, sendo que a efetividade da vacina é comprovada antes do início da vida sexual, e levando em consideração o fato dos pais levarem seus filhos para administração de outras vacinas (SANTOS ACD, et al., 2019).

Muitas vezes, o conhecimento que a população possui sobre o HPV e as vacinas disponíveis são falhos. Podendo isto estar relacionado à maneira como essas informações estão sendo colhidas e repassadas pelos profissionais de diversas áreas, pois a educação continuada deve ser realizada de acordo com a capacidade das diferentes camadas sociais em acessar e processar tais informações (OSIS MJD, et al.,2014; SANTOS ACD, et al.,2019).

É fundamental preservar a confiança nas vacinas e nos profissionais de saúde, para manter a demanda e o uso das vacinas tanto nos países desenvolvidos quanto naqueles em desenvolvimento. A população em sua maioria opta por seguir o esquema vacinal recomendado pelo seu médico ou instituição de saúde, mas é continua a necessidade de enfretamento dos grupos que recusam ou retardam a aplicação das vacinas. Fazendo parte desse grupo, pais de crianças e adolescentes, gestantes, idosos e profissionais da saúde que optam por não se vacinar, não vacinar seus filhos ou não recomendar vacinas aos seus pacientes (DUBÉ E, et al., 2015).

Uma alternativa interessante para fortalecer as atividades de educação em saúde presenciais é a utilização de mídias sociais como estratégia para a promoção da saúde dessa população, sendo este meio de comunicação atualmente o mais influente para este público, uma vez comprovado através de pesquisas o potencial das redes sociais como meio de informação, devido à grande interação dos adolescentes. Promover saúde com foco saúde sexual por meio das redes sociais pode ser um método para atingir essa população, aumentando o conhecimento sobre as ISTs e a redução do comportamento de risco, e também maior adesão à vacina contra o HPV (YOUNG SD e RICE E, 2011; SANTOS CA, et al., 2019).

Outro agente que atua como colaborador para melhorar a efetividade da adesão à vacinação é o Programa Saúde na Escola, mediante ações de prevenção e promoção de saúde, para a formação integral dos estudantes da rede pública de educação básica. Na compreensão de que a escola se torna um espaço com grande potencial para ampliação e garantia do SUS, o PSE instituído em 2007, tem papel fundamental na mudança de visão dos adolescentes e como apoio aos profissionais na área da educação (SANTOS CA, et al., 2019).

As vacinas contra o HPV têm em sua composição a proteína capsídeo L1 do HPV que se reproduz em partículas vírus-like (VLP), que são idênticas ao vírus e adsorvidas no adjuvante sulfato de hidroxifosfato, induzindo resposta humoral com anticorpos de ação neutralizadora. Cada $0,5 \mathrm{ml}$ da vacina contêm compostos para os quatro tipos de vírus, sendo $20 \mu \mathrm{g}$ da proteína HPV6L1, $40 \mu \mathrm{g}$ HPV11L1, $20 \mu \mathrm{g}$ da proteína HPV18L1 e $20 \mu \mathrm{g} \mathrm{HPV16L1,} \mathrm{entre} \mathrm{outros} \mathrm{adjuvantes,} \mathrm{não} \mathrm{contendo} \mathrm{conservantes} \mathrm{ou} \mathrm{antibióticos,} \mathrm{e} \mathrm{nas} \mathrm{embalagens}$ não contém látex (LOBÃO WM, 2018).

A aplicação da vacina estimula uma resposta imune adaptativa para as células $T$ e $B$, se tornando capazes de neutralizar infecções subsequentes com ação específica contra as proteínas do capsídeo viral. Não há risco de ocasionar a doença, tendo em vista que ela não possui o DNA do vírus. Os anticorpos serão liberados com a finalidade de prevenir a infecção primária ou persistem, impedindo o processo infeccioso (ROSA MI, et al., 2009; SILVA MJPMA, et al., 2009, OLIVEIRA MP, et al., 2012).

Atualmente, o Ministério da Saúde oferece a vacina quadrivalente para meninas de 9 a 14 anos de idade e meninos na faixa de 11 a 14, podendo iniciar o esquema com 14 anos completos desde que se complete o esquema até os 15 anos de idade. Outros grupos que se incluem no público-alvo são mulheres e homens entre 9 e 26 anos que sejam portadoras de HIV/AIDS 20. É de grande relevância disponibilizar a vacina para portadores do HIV, pois é o grupo de maior incidência e gravidade do câncer, ampliando a expectativa de vida dessa população, além de reverter a tendência crescente de câncer de ânus em adultos com AIDS, se comparado a proporção geral da população (BRASIL, 2018). 


\section{CONCLUSÃO}

Os dados analisados mostram que a coberta vacinal está insuficiente, e existe uma adesão vacinal maior na primeira dose com relação à segunda dose, em ambos os sexos. Durante os anos em estudo percebe-se uma regressão na cobertura vacinal ao passar dos anos. É necessário que sejam intensificadas as ações de saúde e principalmente educação em saúde em todos os âmbitos possíveis de abrangência do público-alvo preconizado para vacinação, principalmente no que diz respeito ao retorno desses adolescentes a UBS, para cumprimento do calendário vacinal, de maneira que estes possam cada vez mais ser inseridos no contexto vacinal e compreender a importância da vacina como uma medida segura e preventiva conta o HPV. Bem como medidas que tenham foco para os pais e profissionais de saúde, para que estes possam desmistificar diversas impressões sobre a vacinação e fornecer informações corretas aos adolescentes, contribuindo dessa forma para o aumento da cobertura vacinal durante todo o esquema vacinal.

\section{REFERÊNCIAS}

1. AGOSTI JM, GOLDIE SJ. Introducing HPV vaccine in developing countries-keychallengesandissues. New England Journal of Medicine. Massachussetts, 2007; 356(19): 1908-1910.

2. BRASIL. Ministério da Saúde. Secretaria de Vigilância em Saúde. Departamento de Doenças de Condições Crônicas e Infecções Sexualmente Transmissíveis. Protocolo Clínico e Diretrizes Terapêuticas para Atenção Integral às Pessoas com Infecções Sexualmente Transmissíveis (IST). Brasília, 2020.

3. BRASIL. Ministério da Saúde. Coberturas vacinais no Brasil Período: 2010 - 2014. Secretaria de Vigilância em Saúde. Brasília, 2015.

4. BRASIL. Ministério da Saúde. Guia Prático sobre o HPV. Secretaria De Vigilância em Saúde. Departamento De Vigilância De Doenças Transmissíveis. Brasília, 2014.

5. BRASIL. Ministério da Saúde. Informe técnico da ampliação da oferta das vacinas papilomavírus humano $6,11,16$ e 18 (recombinante) - vacina HPV quadrivalente e Meningocócica C (conjugada). Departamento De Vigilância De Doenças Transmissíveis. Brasília, 2018.

6. CAMPOS ERT, et al. Vacina contra papilomas vírus humana: dilemas enfrentados no seio familiar. Revista Intercâmbio, 2017; 9: 131-148.

7. CARNEIRO RF, et al. Educação sexual na adolescência: uma abordagem no contexto escolar. SANARE-Revista de Políticas Públicas, 2015; 14(1):104-108.

8. CONTI FS, et al. Educação e promoção à saúde: comportamento e conhecimento de adolescentes de colégio público e particular em relação ao papilomavírus humano. J bras Doenças Sex Transm, 2006; 18(1): 30-35.

9. DA FONSÊCA EAB, et al. adesão de meninas à campanha de vacinação contra hpv no estado da paraíba em 2014. Revista de Ciências da Saúde Nova Esperança,2017; 15(1): 110-118.

10. LESSA SC, SCHRAMM FR. Proteção individual versus proteção coletiva: análise bioética do programa nacional de vacinação infantil em massa. Ciência \& Saúde Coletiva, 2015; 20:115-124.

11. LOBÃO WM. Avaliação da aceitação parental da vacina HPV após sua introdução no Programa Nacional de Imunização Tese (Doutorado em Biotecnologia em Saúde e Medicina Investigativa) - Instituto Gonçalo Moniz, Fundação Oswaldo Cruz, Salvador, 2018. 93 p.

12. MOURA LL. Cobertura vacinal contra o Papilomavírus Humano (HPV) em meninas e adolescentes no Brasil: análise por coortes de nascimentos. Dissertação (Mestrado em Epidemiologia em Saúde Pública) - Escola Nacional de Saúde Pública Sergio Arouca, Fundação Oswaldo Cruz, Rio de Janeiro, 2019. 91 p.

13. RODEN R, WU TC. How will HPV vaccines affect cervical cancer? Nature Reviews Cancer. Baltimore, 2006; 6(10):753763.

14. ROSA MI, et al. Papilomavírus humano e neoplasia cervical. Cadernos de Saúde Pública, 2009; 25:953-964.

15. SANTOS ACD, et al. Relato de Experiência: Construção e Desenvolvimento do Programa de Saúde na Escola (PSE) sob a Perspectiva da Sexualidade na Adolescência. Revista Brasileira de Educação Médica, Uruguaiana, 2019; 43(4):193-199.

16. SANTOS CA, et al. Internet e HPV: Uma possibilidade para educaçao em saúde entre adolescentes? Adolescencia e Saude, 2019; 16(1): 46-59.

17. PEREIRA IMR. Análise descritiva da cobertura da vacina HPV quadrivalente no Brasil, entre 2016 e 2017. Trabalho de Conclusão de Curso (Bacharelado em Enfermagem) — Universidade de Brasília. Brasília. 2018. 39 p.

18. POMFRET TC, et al. Quadrivalent human papillomavirus (HPV) vaccine: a review of safety, efficacy, and pharmacoeconomics. Journal of clinical pharmacy and therapeutics. Shrewsbury, 2011; 36(1):1-9.

19. WRIGHT TC, et al. Primary cervical cancer screening with human papillomavirus: end of study results from the ATHENA study using HPV as the first-line screening test. Gynecologiconcology, 2015; 136(2): 189-197.

20. YOUNG SD, RICE E. Online social networking technologies, HIV knowledge, and sexual risk and testing behaviors among homeless youth. AIDS andBehavior, 2011; 15(2): 253-260.

21. ZANINI NV, et al. Motivos para recusa da vacina contra o Papilomavírus Humano entre adolescentes de 11 a 14 anos no município de Maringá-PR. Revista Brasileira de Medicina de Família e Comunidade, 2017; 19(39):1-13. 